\title{
Physical Activity Pattern and Its Association with Glycaemic and Blood Pressure Control among People Living with Diabetes (PLWD) In The Ho Municipality, Ghana
}

\author{
James Osei-Yeboah ${ }^{1^{*}}$, William Owiredu ${ }^{2,7}$, Gameli Norgbe $^{3}$, Christian \\ Obirikorang $^{2}$, Sylvester Lokpo ${ }^{1}$, Evans Ashigbi ${ }^{4}$, Beatrice Johnson ${ }^{5}$, Francis \\ Ussher $^{6}$, John Deku ${ }^{1}$, Emmanuel Asiamah ${ }^{1}$, Roseline Avorkliyah ${ }^{1}$, Edward \\ Boakye $^{1}$, Tibemponi Ntoni ${ }^{1}$, Prince Nyamadi ${ }^{1}$ \\ ${ }^{5}$ Department of Nursing, School of Nursing and Midwifrey, University of Health and Allied \\ Sciences, Ho, Ghana \\ ${ }^{6}$ Faculty of Health and Allied Sciences, Koforidua Technical University, Koforidua, Eastern \\ Region, Ghana \\ ${ }^{7}$ Department of Clinical Biochemistry, Diagnostic Directorate, Komfo Anokye Teaching \\ Hospital, Kumasi, Ghana \\ *Email: joyeboah@uhas.edu.gh
}

\author{
OPEN ACCESS \\ Citation: James Osei-Yeboah, William K. \\ B. A. Owiredu, Gameli Kwame Norgbe, \\ Christian Obirikorang, Sylvester Yao \\ Lokpo, Evans Yayra Kwaku Ashigbi, \\ Beatrice Bella Johnson, Francis Abeku \\ Ussher, John Gameli Deku, Emmanuel \\ Akomanin Asiamah ${ }^{1}$, Roseline \\ Avorkliyah, Edward Yiadom Boakye ${ }^{1}$, \\ Tibemponi Ntoni, Prince Senyo Kwasi \\ Nyamadi. Physical Activity Patterns and \\ Its Association with Glycaemic and Blood \\ Pressure Control among People Living \\ with Diabetes (PLWD) In The Ho \\ Municipality, Ghana. Ethiop J Health Sci. \\ 2018;29(1):819. \\ doi:http://dx.doi.org/10.4314/ejhs.v29i1.3 \\ Received: May 14, 2018 \\ Accepted: August 24, 2018 \\ Published: January 1, 2019 \\ Copyright: (C) 2018 Osei-Yeboah et al. \\ This is an open access article distributed \\ under the terms of the Creative Commons \\ Attribution License, which permits \\ unrestricted use, distribution, and \\ reproduction in any medium, provided the \\ original author and source are credited. \\ Funding: Nil \\ Competing Interests: The authors declare \\ that this manuscript was approved by all \\ authors in its form and that no competing \\ interest exists. \\ Affiliation and Correspondence: \\ ${ }^{1}$ Department of Medical Laboratory \\ Sciences, School of Allied Health \\ Sciences, University of Health and Allied \\ Sciences, Ho, Ghana \\ ${ }^{2}$ Department of Molecular Medicine, \\ School of Medical Sciences, Kwame \\ Nkrumah University of Science and \\ Technology, Kumasi, Ghana \\ ${ }^{3}$ School of Allied Health Sciences, \\ University of Health and Allied Sciences, \\ Ho, Ghana \\ ${ }^{4}$ Department of Physiotherapy and \\ Rehabilitation Sciences, School of Allied \\ Health Sciences, University of Health \\ and Allied Sciences, Ho, Ghana
}

\section{ABSTRACT}

BACKGROUND: Physical activity (PA) offers considerable health benefits for diabetic patients. However, extensive high levels of inactivity has been reported among diabetic patients. This study sought to assess the patterns of physical activity and its relationship with two management-relevant outcomes (glycaemic and blood pressure control)among people living with diabetes in the Ho Municipality, Ghana.

METHODS: A hospital-based cross-sectional study was carried out from January 2017 to April 2017 among 150 purposively recruited diabetic patients who were receiving care at the diabetes clinics of the Volta Regional Hospital and the Ho Municipal Hospital. A semi-structured questionnaire was used in capturing socio-demographic information. Physical activity was assessed using the International Physical Activity Questionnaire Short Form. Glycaemic and blood pressure control were evaluated within a three-month period from patients' records.

RESULTS: Physical activity estimates among participants were $21.33 \%, 48 \%$ and $30.67 \%$ for high, moderate and low $P A$ respectively. Glycaemic control among the study participants was $33.33 \%$ and blood pressure control was $58.67 \%$. Both glycaemic and blood pressure control were significantly associated with $P A$. CONCLUSION:In this group of PLWD in the Ho Municipality, high levels of inactivity, uncontrolled glycaemia and blood pressure exist. However, glycaemic and blood pressure control may be modulated by moderate-intensity physical activity.

KEYWORDS: Diabetes, Physical Activity, Glycaemic Control, Blood Pressure Control 


\section{INRODUCTION}

Urbanization and globalization with its attendant pronounced changes in the human environment, behaviour and life-style modification, have resulted in escalating rates of both obesity and diabetes, described as diabesity (1). Currently, the prevalence of Diabetes mellitus has been increasing in Ghana (2,3). Diabetes is a component cause of several other important and often lethal diseases, such as cardiovascular and renal diseases (4). Diabetic conditions, if not well managed, could lead to complications (2). The management of diabetes requires a lifelong intervention which includes frequent selfmonitoring of blood glucose (SMBG), dietary modifications, physical activity and administration of medications as per schedule (5).

The adoption and maintenance of physical activity are critical foci for blood glucose management and overall health in individuals with diabetes (6). Practice guidelines consistently recommend that people with diabetes obtain at least 150 minutes of moderate to vigorous aerobic exercise per week (7). Acute bout of exercise increases glucose disposal into the contracting muscles, leading to clinically significant decreases in blood glucose concentrations (8). Evidence of the benefits of physical activity to diabetes management includes, but not limited to, reduction in weight, increased insulin sensitivity, improved cardiovascular fitness, muscle strength and overall improvement of well-being of people living with diabetes $(6,9)$. Physical inactivity has been linked to increased risk of cardiovascular episodes and all-cause mortality among people living with diabetes $(1,10)$.

Despite the evidence of substantial benefits of physical activity towards clinical management goals in diabetes, a high rate of physical inactivity has been reported among people living with diabetes $(1,11,12)$. There is limited information on physical activity among people living with diabetes in the Ho Municipality. An important initial step for prioritizing, formulation and implementation of a successful intervention is the measuring of current levels of physical activity
(9). This study, sought to assess the patterns of physical activity and its relationship with two management-relevant outcomes, glycaemic and blood pressure control, among people living with diabetes in the Ho Municipality, Ghana.

\section{MATERIALS AND METHODS}

Study population and study design: A hospitalbased cross-sectional study was carried out from January 2017 to April 2017 among 150 purposively recruited patients with diabetes who were receiving medical care at the diabetes clinics of the Volta Regional Hospital and the Ho Municipal Hospital. The study participants were all consenting type 2 diabetes adult patients between the ages of 27 and 84 years, who were not deaf or mute and were not having physical disability or other chronic conditions which could influence physical activity such as stroke and cancer.

Study area: The Ho Municipality is located in the Volta Region. The Ho Municipality also serves as the capital of the Volta Region of Ghana. Ho is the capital of the municipality and the commercial hub of the entire region. The total land size covers 2,361 square kilometers representing 11.5 percent of the region's total land area (13). The total population is 192,871 with 94,951 males and 97,920 females and had a growth rate of $1.17 \%$ in the year 2010 (14).

Sample size determination: Using the average monthly attendance of diabetic patients which was sixty (60) for two previous months (November 2016 and December 2016), a total study population of 260 was generated for the four months study duration, using the Roasoft online sample size calculator (Roasoft Inc, 2004, http://www.raosoft.com/samplesize.html). The recommended minimum sample of 148 diabetic participants was calculated at 95\% confidence level, 5\% margin of error, and a response distribution of $50 \%$ based on the average number of diabetic patients that visited the clinic in the previous months.

Socio-demographic and physical activity capture: A self-reported, semi-structured questionnaire was used to collect information on

DOI: http://dx.doi.org/10.4314/ejhs.v29i1.3 
age, gender, marital status, educational background, employment status, duration of diabetes and type of medication. Physical activity was assessed using the pre-validated seven item International Physical Activity Questionnaire Short Form (IPAQ-SF)(15).

International physical activity questionnaire (IPAQ): The IPAQ-SF was administered by a face-to-face interview by the investigators in the participants' preferred language (English, Ewe or Twi) or self-administered by those who were literate. The IPAQ was developed as an instrument for cross national monitoring of physical activity and inactivity across diverse countries and populations (16). The IPAQ-SF consists of three physical activity components/domain (Walking activity, Moderateintensity activity and Vigorous-intensity activity). The IPAQ-SF scoring mechanism allows for both categorical and continuous estimation of physical activity. The continuous scores are equivalent to weekly energy expenditure measured in Metabolic Equivalent of Task - minutes per week (MET minutes/week), whiles the categorical score rates the physical activity into Highly active, Moderately active and Low(inactive or sedentary) (17).

Biochemical and haemodynamic parameters: With a regular clinic attendance interval of 6 weeks, fasting blood glucose and blood pressure measurement as well as values for two previous visits within a 3 month period were recorded from patients' folders.Glycaemic control was defined as consistent fasting blood glucose levels of 4 to $7 \mathrm{mmol} / \mathrm{L}$ for the three recorded readings. Controlled blood pressure was defined as consistent blood pressure reading of < 140/90mmHg systolic/diastolic blood pressure for the three recorded readings.

Statistical analysis: Categorical variables were expressed as frequency and proportion. Continuous non-parametric variables were presented as medians. Differences between proportions were tested with Fisher exact or chi square test where appropriate. Differences between medians were tested with KolmogorovSmirnov test. Association between continuous variables was assessed using Spearman correlation. A p-value of less than 0.05 was considered as significant at all points of the analysis. Data analysis was done using IBM Statistical Package for the Social Sciences version 22.00. (SPSS Inc, Chicago, USA; www.spss.com).

Psychometric properties of the IPAQ: The internal consistency reliability for the IPAQ was tested using the Cronbach's alpha reliability method. The overall Cronbach alpha was 0.742 and the Cronbach's alpha based on standardized items was 0.776 . The reliability for Walking activity was 0.709 , for Moderate-intensity activity was 0.660 and Vigorous-intensity activity was 0.757 .

Ethical consideration: Informed consent was obtained from all participants after the study procedure was clearly explained to them in a language they understood (English, Ewe or Twi). Approval for the study was obtained from the facilities at both the Volta Regional Hospital (VRH) and the Ho Municipal Hospital. Ethical Clearance for the study was granted by the Ethical Review and Scientific Committee of the School of Allied Health Sciences of the University of Health and Allied Sciences, Ho (UHAS-SAHSERSC:0016A/2017). No patient was denied the appropriate care for declining to participate in the study. Confidentiality of participant's data was ensured and analysis of data was anonymous and non-linked.

\section{RESULTS}

The majority of the study respondents were females, 109(72.67\%) and married, 106(70.67\%). At the time of the study, 34\% of the respondents had attained tertiary education, $11.33 \%$ had secondary and $43.33 \%$ had basic education. The majority of the participants $(51.33 \%)$ were employed in the informal sector. With the exception of $8.67 \%$ who were on insulin and $2.66 \%$ who were on both insulin and oral medications, all the participants were on oral medications (Table 1). 
Table 1: Socio-Demographic characteristics of Diabetes patients in Ho

\begin{tabular}{lcc}
\hline Parameter & Frequency & Percentage \\
\hline Total & 150 & 100 \\
Facility & & \\
Municipal & 96 & 64.00 \\
Regional & 54 & 36.00 \\
Gender & & \\
Male & 41 & 27.33 \\
Female & 109 & 72.67 \\
Marital Status & & \\
Single & 44 & 29.33 \\
Married & 106 & 70.67 \\
Educational Background & & \\
None & 17 & 11.33 \\
Basic & 65 & 43.33 \\
Secondary & 17 & 11.33 \\
Tertiary & 51 & 34.00 \\
Employment Status & & \\
None & 17 & 11.33 \\
Formal & 56 & 37.33 \\
Informal & 77 & 51.33 \\
Type of Treatment & & 88.67 \\
Oral Drug & 133 & 8.67 \\
Both & 13 & 2.66 \\
\hline Data presented as frequency and percentage & 4 & \\
& &
\end{tabular}

Data presented as frequency and percentage

Fifty (50) participants representing 33.33\% presented with plasma glucose levels within the normal range, and $58.67 \%$ had their blood pressure controlled. Controlled blood pressure was predominantly higher among patrons of the Municipal Hospital (64.58\%) compared to those who attended clinic at the Regional Hospital (48.15\%) (Table 2).

Table 2: Glycaemic and blood pressure control among people living with diabetes in the Ho Municipality stratified by gender and facility.

\begin{tabular}{lcccc}
\hline Gender & Total & Male & Female & p-value \\
\hline Glycaemic Control & $\mathbf{1 5 0 ( 1 0 0 )}$ & $\mathbf{4 1 ( 2 7 . 3 3 )}$ & $\mathbf{1 0 9 ( 7 2 . 6 7 )}$ & 1 \\
Controlled BP & $50(33.33)$ & $14(34.15)$ & $36(33.03)$ & 0.2807 \\
\hline \multirow{2}{*}{ Facility } & $88(58.67)$ & $66(60.15)$ & $22(53.66)$ & p-value \\
\hline Glycaemic Control & Total & Municipal & Regional & 1 \\
Controlled BP & $\mathbf{1 5 0 ( 1 0 0 )}$ & $\mathbf{9 6 ( 6 4 . 0 0 )}$ & $\mathbf{5 4 ( 3 6 . 0 0 )}$ & 0.0370 \\
\hline
\end{tabular}

Data presented as frequency with corresponding percentage in parenthesis; BP- Blood pressure; $p$ - significant at 0.05

DOI: http://dx.doi.org/10.4314/ejhs.v29i1.3 
For most of the diabetic patients who engaged in physical activity (PA), walking was the physical activity of choice, 140(93.33\%), followed by those who engaged in moderate physical activity, $101(67.33 \%)$, and $15(10.00 \%)$ participated in vigorous physical activity. Among participants that engaged in walking, 86 also do moderate PA, and 14 did vigorous PA and moderate PA in addition to the walking. Gender difference in terms of physical activity pattern was not statistically significant. However, a slightly higher proportion of males were engaged in vigorous and moderate physical activities compared to females. Generally, respondents who had achieved glycaemic control were found to engage in more physical activity than those without glycaemic control. No significant difference in the patterns of physical activity was observed for respondents with controlled blood pressure and those without (Table 3).

Table 3: Physical activity patterns in people living with Diabetes in the Ho Municipality stratified by gender and clinical end-point

\begin{tabular}{cccc}
\hline Gender & Female & Male & p-value \\
\hline Vigorous PA & $8(7.34)$ & $7(17.07)$ & 0.1222 \\
Moderate PA & $73(66.97)$ & $28(68.29)$ & 1 \\
Walking PA & $102(93.58)$ & $38(92.68)$ & 1 \\
Glycaemia & Controlled & Not Controlled & \\
\hline Vigorous PA & $6(12.00)$ & $9(9.00)$ & 0.5733 \\
Moderate PA & $40(80.00)$ & $61(61.00)$ & 0.0261 \\
Walking PA & $50(100)$ & $90(90.00)$ & 0.0311 \\
Blood Pressure & Controlled & Not Controlled & \\
\hline Vigorous PA & $6(6.82)$ & $9(14.52)$ & 0.1671 \\
Moderate PA & $64(72.73)$ & $37(59.68)$ & 0.1125 \\
Walking PA & $83(94.32)$ & $57(91.94)$ & 0.7415 \\
\hline
\end{tabular}

Data presented as frequency with corresponding proportion in parenthesis; PA-Physical Activity; p- isignificant at 0.05

The median Total Metabolic Equivalent of Task (MET) was 1,603 (minutes/week) for the general population. The female and male study participants had MET of 1,599.5 (minutes/week) and 1,624 (minutes/week) respectively. The median MET for vigorous physical activity, moderate physical activity and walking were 0 (minutes/week), 700 (minutes/week) and 693 (minutes/week) respectively. No significant gender variation in median MET was observed. With the exception of the vigorous activity component, participants with glycaemic control presented a higher median MET in all the components of physical activity compared with their counterparts without glycaemic control. Participants with controlled blood pressure presented a higher median MET for the walking component of physical activity than participants presenting with high blood pressure (Table 4).

DOI: http://dx.doi.org/10.4314/ejhs.v29i1.3 
Table 4: Median Metabolic Equivalent of Task per week among people living with diabetes in the Ho Municipality

\begin{tabular}{lcccc}
\hline Gender & Total & Female & Male & p-value \\
\hline Total MET & 1603.00 & 1599.50 & 1624.00 & 0.665 \\
Vigorous MET & 0.00 & 0.00 & 0.00 & 0.94 \\
Moderate MET & 700.00 & 700.00 & 840.00 & 0.65 \\
Walking MET & 693.00 & 693.00 & 693.00 & 0.99 \\
Glycaemia & Total & Controlled & Not Controlled & p-value \\
\hline Total MET & 1603.00 & 2119.50 & 1186.50 & 0.005 \\
Vigorous MET & 0.00 & 0.00 & 0.00 & 1 \\
Moderate MET & 700.00 & 1080.00 & 560.00 & 0.01 \\
Walking MET & 693.00 & 693.00 & 462.00 & 0.002 \\
Blood Pressure & Total & Controlled & Not Controlled & p-value \\
\hline Total MET & 1603.00 & 1879.50 & 1253.00 & 0.164 \\
Vigorous MET & 0.00 & 0.00 & 0.00 & 0.982 \\
Moderate MET & 700.00 & 840.00 & 560.00 & 0.525 \\
Walking MET & 693.00 & 693.00 & 462.00 & 0.014 \\
\hline
\end{tabular}

Data presented as median metabolic equivalent task minutes per week; p-significant at 0.05 ; MET- Metabolic Equivalent Task $=$ Minute scores equivalent to Kilocalories for a 60 Kilogram person

In general, aging was associated with decreasing physical activity among the general study population. Among the female respondents, glycaemic control was negatively associated with the total metabolic equivalent task representing the overall physical activity and the walking component of physical activity. Blood pressure control was negatively associated with overall physical activity and the moderate physical activity component (Table 5).

Table 5: Spearman correlation of clinical outcome variables and physical activity scores. Female subpopulation (Upper right-hand side) and Male subpopulation (Lower left-hand side)

\begin{tabular}{llllllllll}
\hline Parameter & Age & Duration & FBG & SBP & DBP & METW & METM & METV & TMET \\
\hline Age & & $.19^{*}$ & -0.13 & $0.40^{* *}$ & 0.19 & $-.22^{*}$ & $-.28^{* *}$ & -0.13 & $-0.31^{* *}$ \\
Duration & 0.22 & & 0.1 & 0.15 & -0.06 & -0.15 & -0.12 & $-0.24^{*}$ & $-0.19^{*}$ \\
FBS & 0.17 & 0.04 & & 0.01 & 0.04 & $-.32^{* *}$ & -0.19 & -0.03 & $-0.22^{*}$ \\
SBP & 0.07 & -0.25 & 0.2 & & $0.55^{* *}$ & -0.19 & $-0.23^{*}$ & -0.08 & $-0.23^{*}$ \\
DBP & 0.15 & -0.14 & 0.18 & $0.42^{* *}$ & & -0.18 & $-0.23^{*}$ & 0.08 & $-0.20^{*}$ \\
METW & $-0.63^{* *}$ & -0.22 & -0.18 & -0.06 & -0.17 & & $0.51^{* *}$ & $0.21^{*}$ & $0.71^{* *}$ \\
METM & $-0.44^{* *}$ & -0.22 & 0.02 & 0.22 & -0.13 & $0.68^{* *}$ & & $0.30^{* *}$ & $0.93^{* *}$ \\
METV & -0.15 & 0.05 & 0.05 & 0.28 & 0.25 & 0.24 & $.40^{* *}$ & & $0.44^{* *}$ \\
TMET & $-0.51^{* *}$ & -0.2 & -0.05 & 0.24 & 0.03 & $0.76^{* *}$ & $0.89^{* *}$ & $0.63^{* *}$ & \\
\hline
\end{tabular}

Data is presented as coefficient of spearmen correlation; *p- significant at 0.05 ; * p- significant 0.01 ; FBG-Fasting blood glucose, SBP-Systolic blood pressure, DBP-Diastolic blood pressure, MET-Metabolic Equivalent Task -minutes/week; METW-Walking MET-minutes/week; METM-Moderate; MET-minutes/week; METV-Vigorous MET-minutes/week; TMET-Total physical activity; MET- minutes/week

DOI: http://dx.doi.org/10.4314/ejhs.v29i1.3 
Significantly higher percentage of patients, presenting with glycaemic control, were found to have engaged in physical activity in comparison to their counterparts whose glucose levels were higher than optimal $(p=0.0238)$. In the continuum of physical activity, $22.00 \%$ of patients with glycaemic control engaged in high physical activity, $60.00 \%$ engaged in moderate physical activity and $18.00 \%$ in low physical activity compared to $37.00 \%$ of those without glycaemic control found to engage in low physical activity
(Figure 1A). Though not statistically significant, higher percentages of those with controlled blood pressure were engaged in physical activity (73.9\%) compared to those without blood pressure control (62.9\%). For those with controlled blood pressure, the majority were engaged in moderate physical activity $(55.7 \%)$ while $26.1 \%$ were engaged in low physical activity compared to $37.1 \%$ of those presenting with high blood pressure engaging in low physical activity (Figure 1B).
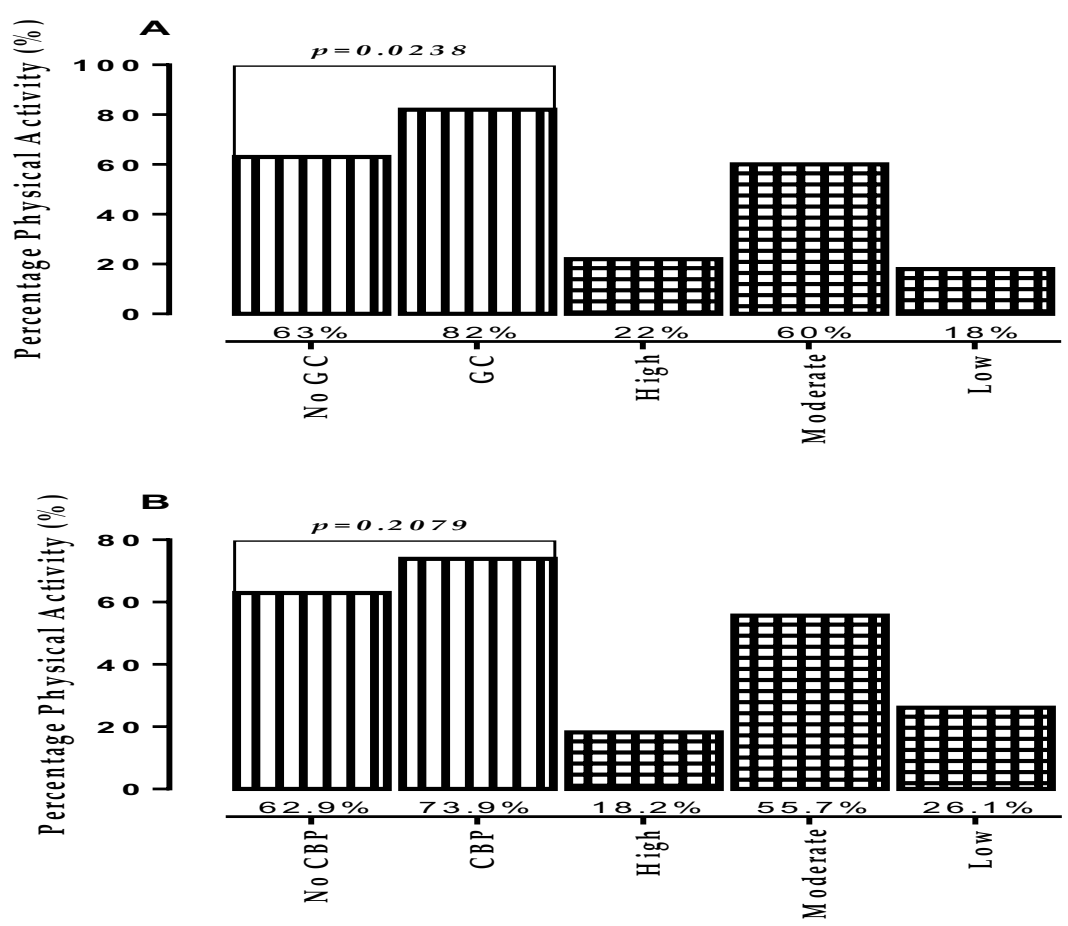

Figure 1: Relation between physical activity, glycaemic and blood pressure control among people living with diabetes in the Ho Municipality; GC-Glycaemic Control; CBP-Controlled Blood Pressure; $p$ significant at 0.05

\section{DISCUSSION}

The demographic characteristics of the study population compared well with that of similar researches conducted locally (18-20) and within the sub-region (21). However, the study participants in this study were comparatively more educated compared to those in the work of Awodele and Osuolale (21).
Poor glycaemic control is acknowledged as the major contributing factor to diabetes complications (22). Only one third of the current study population had their plasma glucose levels controlled. This finding compared favourably with that of Titty (23) in Tamale (40\%), Chinenye, Uloko (24) in Nigeria (32.4\%) and Musenge, Manankov (25) in Zambia (38.7\%). However the rate of poor glycaemic control recorded in this study is higher than that reported 
by Kamuhabwa and Charles (26) in Tanzania $(23.9 \%)$ and BeLue, Ndiaye (27) in Senegal $(24.8 \%)$.

In this study, the choice of physical activity among people living with diabetes was skewed, with participation in the order of walking, moderate physical activity and a few engaging in vigorous physical activities (Table 3 ). The pattern of physical activity observed in this study agrees with earlier reports in diabetic populations. Due to economic circumstances, populations in developing countries are more likely to walk longer distances because of lower ownership of vehicles and high transport fares (12).

As seen in Table 4, except for vigorous physical activity, the median energy expenditure in the current study was higher compared to those reported by Oyewole, Odusan (1). Metabolic equivalence of task scores are normally nonparametric data, and contrary to recommendations by the IPAQ Research Committee (15), other works cited in the literature presented the MET scores as means instead of medians. Therefore, making comparison with this study is not plausible $(9,12,28,29)$.

Respondents' self-reported engagement in physical activity was classified as high physical activity (21.33\%), moderate physical activity $(48 \%)$ and low physical activity (inactive or sedentary, 30.67\%). Among a cohort of Nigerian diabetics, Ojoawo and Ogunbeku (30) reported $33 \%$ high physical activity level, $41 \%$ moderate level of physical activity and 26\% low physical activity level. Oyewole, Odusan (1) and Adeniyi, Ogwumike (31) also found that $31 \%$ and $68.7 \%$ respectively of diabetic patients in Nigeria were physically inactive. In Rwanda, Kabanda and Phillips (12) found that $39 \%$ of people living with diabetes were inactive. Similar findings have been reported in other non-African jurisdictions. Shazwani, Suzana (32) reported 20\% high, 47\% moderate and $33.33 \%$ low physical activity among people living with diabetes in Malaysia.

Gleaned correlates of physical inactivity from previous studies is skewed toward the older age group, and women living with diabetes $(1,12,29,30,33)$. In conformity with earlier findings, older age was negatively associated with physical activity (Table 5). Kabanda and Phillips (12) posited that the apparently low levels of physical activity among older patients is due to lack of self-esteem, poor health status and feelings of fatigue. In this study, no statistically significant gender variation in physical activity was observed, though in most cases, percentage and median scores of physical activity were higher in the males (Tables 3-4).

Significantly, participants with glycaemic control were found to engage in more moderate and walking components of physical activity, and this culminated into a significantly higher median total energy expenditure and component moderate and walking metabolic equivalents of tasks in this group (Tables 3 and 4). Overall, 20\% of those inactive as compared to $39.4 \%$ of the active population had blood glucose levels within the control limit. Among the female respondents, the glucose level was negatively associated with the total metabolic equivalent of task for the overall and the walking component of physical activity.

The reducing effect of physical activity on glucose levels among people living with diabetes has been well acknowledged in literature over the years (6,8,32,34-41). Among postulations of the mechanism(s) of physical activity on glucose control in diabetes are normalization of impaired insulin-stimulated glucose transporter type 4 (GLUT4) translocation associated with people with type 2 diabetes with concomitant increased insulin sensitivity (8), increased glycogen synthase and hexokinase activity resulting in increased glycogen synthesis and increased nonoxidative disposal of glucose (33), increased messenger RNA, decreased release and increased clearance of free fatty acids, increased muscle glucose delivery due to increased muscle capillary density and changes in muscle composition favouring increased glucose disposal (34).

The antihypertensive effect of being physically active was apparent in this study. The median energy expenditure for walking was significantly higher among persons with controlled blood pressure. Increased blood pressure was also negatively associated with the

DOI: http://dx.doi.org/10.4314/ejhs.v29i1.3 
overall and the moderate physical activity component among female participants (Tables 4 and 5). The hypothesized mechanisms of the antihypertensive effect of physical activity include direct pathways such as neuro-humoral, vascular and structural adaptations (42). Though many stages of these mechanisms are yet to be elucidated, it is thought to function under the form of reflex arches composed of receptors, afferent pathways, integrator centers, efferent pathways and effectors (43). Specifically, the mechanical activation of the calcium-calmodulin controlled endothelial nitric oxide synthase (eNOS) (44), decrease in sympathetic nerve activity due to decreased circulating catecholamines (45) and genetic links to race-dependent responses to exercise stimuli $(42,46)$, are said to be some of the attributes.

In the continuum of physical activity, glycaemic and blood pressure control peaked at moderate physical activity since the majority of patients with optimal outcomes were engaged in moderate physical activity (Figure 1). According to Tanasescu, Leitzmann (47), moderate-intensity activities are associated with improvement in lipoprotein profile and glucose control. Moderate physical activity like walking for at least $30 \mathrm{~min}$ per day has been shown to improve glycaemic control and reduce the risk of cardiovascular event in diabetics by approximately 50\% (48). Tanasescu, Leitzmann (47), therefore, recommended an early initiation of moderate physical activity in the management strategy of diabetics to prevent macrovascular complications and death.

In conclusion, in this group of patients living with diabetes in the Ho Municipality, high levels of sedentariness, uncontrolled glycaemia and blood pressure exist. However, the two treatment outcomes (Glycaemic and Blood pressure control) may be modulated by moderate-intensity physical activity.

\section{REFERENCES}

1. Oyewole O, Odusan O, Oritogun K, Idowu A. Physical activity among type- 2 diabetic adult Nigerians. Annals of African Medicine. 2014;13(4):189-94. doi: 10.4103/15963519.142290 .

2. Darkwa S. Prevalence of diabetes mellitus and resources available for its management in the Cape Coast Metropolis. ISABB Journal of Health and Environmental Sciences. 2011;1(1):1-7.

3. Gatimu SM, Milimo BW, Sebastian MS. Prevalence and determinants of diabetes among older adults in Ghana. BMC Public Health. 2016;16(1):1174. doi: 10.1186/s12889-016-3845-8.

4. Hall V, Thomsen RW, Henriksen O, Lohse N. Diabetes in Sub Saharan Africa 1999-2011: Epidemiology and public health implications. a systematic review. BMC Public Health. 2011;11(1):564. doi: 10.1186/1471-2458-11564.

5. Sharma T, Kalra J, Dhasmana D, Basera H. Poor adherence to treatment: A major challenge in diabetes. Journal, Indian Academy of Clinical Medicine. 2014; $15(1): 40$.

6. Colberg SR, Sigal RJ, Yardley JE, Riddell MC, Dunstan DW, Dempsey PC, et al. Physical Activity/Exercise and Diabetes: A Position Statement of the American Diabetes Association. Diabetes Care. 2016;39(11):2065-79. doi: $10.2337 /$ dc161728.

7. Armstrong MJ, Sigal RJ. Exercise as medicine: key concepts in discussing physical activity with patients who have type 2 diabetes. Canadian journal of diabetes. 2015;39:S129-S33.

8. Musi N, Fujii N, Hirshman MF, Ekberg I, Fröberg S, Ljungqvist $\mathrm{O}$, et al. AMP-activated protein kinase (AMPK) is activated in muscle of subjects with type 2 diabetes during exercise. Diabetes. 2001;50(5):921-7.

9. Ranasinghe DC, Ranasinghe P, Jayawardena R, Matthews DR, Katulanda P. Evaluation of physical activity among adults with diabetes mellitus from Sri Lanka. International 
Archives of Medicine. 2014;7:15-. doi: 10.1186/1755-7682-7-15.

10. Wei M, Gibbons LW, Kampert JB, Nichaman MZ, Blair SN. Low cardiorespiratory fitness and physical inactivity as predictors of mortality in men with type 2 diabetes. Annals of internal medicine. 2000;132(8):605-11.

11. Brazeau A-S, Rabasa-Lhoret R, Strychar I, Mircescu H. Barriers to physical activity among patients with type 1 diabetes. Diabetes care. 2008;31(11):2108-9.

12. Kabanda A, Phillips J. Physical activity among adults with diabetes mellitus in Rwanda: physical activity, health and wellness. African Journal for Physical Health Education, Recreation and Dance. 2011;17(2):239-47.

13. GSS. 2010 Population and Housing Census, District Analytical Report, Ho Municipality. Accra: Ghana Ststistical Service, 2014.

14. HMA. The Composite Budget of the Ho Municipal Assembly for the 2014 Fiscal Year. Ho: Ho Municipal Assembly, 2014.

15. IPAQ Research Committee. Guidelines for Data Processing and Analysis of the International Physical Activity Questionnaire (IPAQ) - Short and Long Forms. 2005;Available from: http://www.ipaq.ki.se. on 27/06/2017, 15:23.

16. 16. Craig CL, Marshall AL, Sjöström M, Bauman AE, Booth ML, Ainsworth BE, et al. International physical activity questionnaire: 12-country reliability and validity. Medicine \& Science in Sports \& Exercise. 2003;35(8):1381-95.

17. Sjostram M, Ainsworth B, Bauman A, Bull F, Craig C, Sallis J. Guidelines for data processing and analysis of the International Physical Activity Questionnaire (IPAQ)-short and long forms: Nov 2005. Available at wwwipaqkise/scoring Accessed. 2009;5(11).

18. Eghan B, Frempong MT, Adjei-Poku M. Prevalence and predictors of microalbuminuria in patients with diabetes mellitus: a cross-sectional observational study in Kumasi, Ghana. Ethnicity and Disease. 2007;17(4):726.
19. Brenyah R, Ephraim R, Owiredu W, Eghan B, Quaye L. Prevalence and determinants of proteinuria among type 2 diabetics in Kumasi, Ghana. Journal of Medical and Biomedical Sciences. 2013;2(1).

20. Ephraim R, Arthur E, Owiredu WKBA, Adoba P, Agbodzakey H, Eghan B. Chronic kidney disease stages among diabetes patients in the Cape Coast Metropolis. Saudi Journal of Kidney Diseases and Transplantation. 2016;27(6):1231-8. doi: 10.4103/13192442.194658 .

21. Awodele O, Osuolale JA. Medication adherence in type 2 diabetes patients: study of patients in Alimosho General Hospital, Igando, Lagos, Nigeria. African Health Sciences. 2015;15(2):513-22.

22. Litwak L, Goh S-Y, Hussein Z, Malek R, Prusty V, Khamseh ME. Prevalence of diabetes complications in people with type 2 diabetes mellitus and its association with baseline characteristics in the multinational A1chieve study. Diabetology \& Metabolic Syndrome. 2013;5(1):57. doi: 10.1186/17585996-5-57.

23. Titty FK. Glycaemic control, dyslipidaemia and metabolic syndrome among recently diagnosed diabetes mellitus patients in Tamale Teaching Hospital, Ghana. West Afr J Med. 2010;29(1):8-11.

24. Chinenye S, Uloko A, Ogbera A, Ofoegbu E, Fasanmade O, Fasanmade A, et al. Profile of Nigerians with diabetes mellitus - Diabcare Nigeria study group (2008): Results of a multicenter study. Indian Journal of Endocrinology and Metabolism. 2012;16(4):558-64. doi: 10.4103/22308210.98011 .

25. Musenge EM, Manankov A, Mudenda B, Michelo C. Glycaemic control in diabetic patients in Zambia. The Pan African medical journal. 2014;19.

26. Kamuhabwa AR, Charles E. Predictors of poor glycemic control in type 2 diabetic patients attending public hospitals in Dar es Salaam. Drug, Healthcare and Patient Safety. 2014;6:155-65. doi: 10.2147/DHPS.S68786.

DOI: http://dx.doi.org/10.4314/ejhs.v29i1.3 
27. BeLue R, Ndiaye K, NDao F, Ba FNN, Diaw M. Glycemic Control in a Clinic-Based Sample of Diabetics in M'Bour Senegal. Health Education \& Behavior. 2016;43(1_suppl):112S-6S. doi: doi:10.1177/1090198115606919.

28. Duarte CK, Almeida JCd, Merker AJS, Brauer FdO, Rodrigues TdC. Nível de atividade física e exercício físico em pacientes com diabetes mellitus. Revista da Associação Médica Brasileira. 2012;58:21521.

29. Thomas N, Alder E, Leese G. Barriers to physical activity in patients with diabetes. Postgraduate medical journal. 2004;80(943):287-91.

30. Ojoawo AO, Ogunbeku M. Assessment of level of physical activity in patients with type 2 Diabetes Mellitus. Sports Medicine Journal/Medicina Sportivâ. 2012;8(1).

31. Adeniyi A, Ogwumike O, Oguntola D, Adeleye J. Interrelationship among physical activity, quality of life, clinical and sociodemographic characteristics in a sample of Nigerian patients with type 2 diabetes. African Journal of Physiotherapy and Rehabilitation Sciences. 2015;7(1-2):12-8.

32. Shazwani N, Suzana S, Hanis Mastura Y, Lim C, Teh S, Mohd Fauzee M, et al. Assessment of Physical Activity Level among Individuals with Type 2 Diabetes Mellitus at Cheras Health Clinic, Kuala Lumpur. Malaysian journal of nutrition. 2010;16(1).

33. $\mathrm{Hu} \mathrm{G}$, Jousilahti $\mathrm{P}$, Barengo $\mathrm{NC}$, Qiao Q, Lakka TA, Tuomilehto J. Physical activity, cardiovascular risk factors, and mortality among Finnish adults with diabetes. Diabetes Care. 2005;28(4):799-805.

34. Boule NG, Haddad E, Kenny GP, Wells GA, Sigal RJ. Effects of exercise on glycemic control and body mass in type 2 diabetes mellitus: a meta-analysis of controlled clinical trials. JAMA. 2001;286. doi: 10.1001/jama.286.10.1218.

35. Dunstan DW, Daly RM, Owen N, Jolley D, De Courten M, Shaw J, et al. High-intensity resistance training improves glycemic control in older patients with type 2 diabetes.
Diabetes Care. 2002;25. doi: 10.2337/diacare.25.10.1729.

36. Ivy JL. Role of exercise training in the prevention and treatment of insulin resistance and non-insulin-dependent diabetes mellitus. Sports Med. 1997;24. doi: 10.2165/00007256199724050-00004.

37. Maiorana A, O'Driscoll G, Goodman C, Taylor R, Green D. Combined aerobic and resistance exercise improves glycemic control and fitness in type 2 diabetes. Diabetes Res Clin Pract. 2002;56. doi: 10.1016/s01688227(01)00368-0.

38. Sigal RJ, Kenny GP, Boule NG, Wells GA, Prud'homme D, Fortier M, et al. Effects of aerobic training, resistance training, or both on glycemic control in type 2 diabetes: a randomized trial. Ann Intern Med. 2007;147. doi: 10.7326/0003-4819-147-6-20070918000005 .

39. Sigal RJ, Kenny GP, Wasserman DH, Castaneda-Sceppa C, White RD. Physical activity/exercise and type 2 diabetes: a consensus statement from the American diabetes association. Diabetes Care. 2006;29. doi: $10.2337 / \mathrm{dc} 06-9910$.

40. Snowling NJ, Hopkins WG. Effects of different modes of exercise training on glucose control and risk factors for complications in type 2 diabetic patients: a meta-analysis. Diabetes Care. 2006;29. doi: 10.2337/dc06-1317.

41. Trovati M, Carta Q, Cavalot F, Vitali S, Banaudi C, Lucchina PG, et al. Influence of physical training on blood glucose control, glucose tolerance, insulin secretion, and insulin action in non-insulin-dependent diabetic patients. Diabetes Care. 1984;7. doi: 10.2337/diacare.7.5.416.

42. Gopinath B, Hardy LL, Teber E, Mitchell P. Association between physical activity and blood pressure in prepubertal children. Hypertens Res. 2011;34(7):851-5.

43. Monteiro MdF, Sobral FDC. Physical exercise and blood pressure control. Revista Brasileira de Medicina do Esporte. 2004;10(6):513-6.

44. Korsager LM, Matchkov VV. Hypertension and physical exercise: The role of oxidative

DOI: http://dx.doi.org/10.4314/ejhs.v29i1.3 
stress. Medicina. 2016;52(1):19-27. doi: http://dx.doi.org/10.1016/j.medici.2016.01.00 5.

45. MacDonald JR. Potential causes, mechanisms, and implications of post exercise hypotension. Journal of human hypertension. 2002;16(4):225.

46. Diaz KM, Shimbo D. Physical Activity and the Prevention of Hypertension. Current hypertension reports. 2013;15(6):659-68. doi: 10.1007/s11906-013-0386-8.
47. Tanasescu M, Leitzmann MF, Rimm EB, Hu FB. Physical Activity in Relation to Cardiovascular Disease and Total Mortality Among Men With Type 2 Diabetes. Circulation. 2003;107(19):2435-9. doi: 10.1161/01.cir.0000066906.11109.1f.

48. amasaki H. Daily physical activity and type 2 diabetes: A review. World Journal of Diabetes. 2016;7(12):243-51. doi: 10.4239/wjd.v7.i12.243. 